\title{
Microstructure and mechanical property of resistance spot welded joint between pure titanium and stainless steel with interlayer of $\mathrm{Nb}$
}

\author{
Longlong Houa, Ranfeng Qiub ,Lihu Cui, Zhongbao Shen, Qingzhe Li \\ School of Materials Science and Engineering, Henan University of Science and Technology, \\ Luoyang, 471003, China \\ Collaborative Innovation Center of Nonferrous Metals, Luoyang 471003, China \\ ahl180226@163.com, 'biurf1221@163.com
}

\begin{abstract}
KEYWORD: Titanium, Stainless steel, Interlayer, Resistance Spot Welding
ABSTRACT: Commercially pure titanium and stainless steel sheets were welded using resistance spot welding with interlayer of $\mathrm{Nb}$. The interfacial microstructure was observed, the effects of welding current on nugget diameter and tensile shear load were investigated deeply. The results show that the interfacial reaction products were consisted of $\mathrm{Nb}$ and $\mathrm{FeNb}$ eutectic structure. The joint with the maximum tensile shear load of $5.61 \mathrm{kN}$ was obtained at the condition of $10 \mathrm{kA}$. It reveals that it is effective to weld titanium and stainless steel using resistance spot welding with an interlayer of $\mathrm{Nb}$.
\end{abstract}

\section{Introduction}

With the rapid advances in the development of modern industry and technology, the requirements of the comprehensive performance of the components are higher. A single metal structure is often hard to meet the needs of industrial production. The titanium/stainless steel joint have comprehensive advantages of the two materials. It not only saves material, but also improves the reliability of system structure. Therefore, the achievement of a sound joining technique between titanium and stainless steel connections will be inevitable. However, there are some difficulties to weld titanium and stainless steel, because of the great differences in thermal, physical, and chemical properties. Hence, some welding methods have been studied in the last few years to obtain a sound joint, such as electron beam welding [1], diffusion bonding [2], soldering [3] and explosive welding [4]. Although the joints acquired by the above means show reasonable performance to a certain extent, the performance of the joints still need to be further improved.

Owing to the advantages of low cost, easy automation, minimum skill requirements, and high production efficiency, resistance spot welding would be a widely used and important welding process in plate manufacturing. However, few studies concerning resistance spot welding of titanium and steel have been reported so far. In the present study, commercially pure titanium and stainless steel sheets were welded using resistance spot welding with interlayer of $\mathrm{Nb}$. Meanwhile, we investigated the interfacial microstructure and mechanical property of the joint deeply, and provide some fundamental information for improving properties of the joint between titanium and stainless steel.

\section{Experimental MATERIALS AND METHODS}

\section{Experimental Materials}

The base materials used in this study were $1.0 \mathrm{~mm}$ thick plates of commercially pure titanium (Ti) sheet and stainless steel (SUS304). The chemical compositions are listed in Table 1. Nb foil of $30 \mathrm{~mm} \times 30 \mathrm{~mm} \times 0.09 \mathrm{~mm} \mathrm{~mm}$ was used as the interlayer. 
Table1. Chemical composition of SUS304 and Ti (mass \%)

\begin{tabular}{cccccccc}
\hline Materials & \multicolumn{7}{c}{ Elements (mass \%) } \\
\hline \multirow{2}{*}{ SUS304 } & $\mathrm{Fe}$ & $\mathrm{Cr}$ & $\mathrm{Ni}$ & $\mathrm{Mn}$ & $\mathrm{Si}$ & $\mathrm{C}$ & $\mathrm{P}$ \\
& $\mathrm{Bal}$. & 18.0 & 8.0 & 1.25 & 0.85 & 0.06 & 0.04 \\
& $\mathrm{Ti}$ & $\mathrm{Fe}$ & $\mathrm{O}$ & $\mathrm{H}$ & $\mathrm{N}$ & & \\
$\mathrm{Ti}$ & $\mathrm{Bal}$ & 0.20 & 0.15 & 0.013 & 0.05 & & \\
\hline
\end{tabular}

\section{Experimental Methods}

Resistance spot welding was carried out by a DC spot welding machine. Fig. 1 shows the schematic diagram of this welding process. The welding current was changed every $2 \mathrm{kA}$ between 8 and $14 \mathrm{kA}$ at the fixed electrode force of $2807 \mathrm{~N}$ and welding time of 10 cycles.

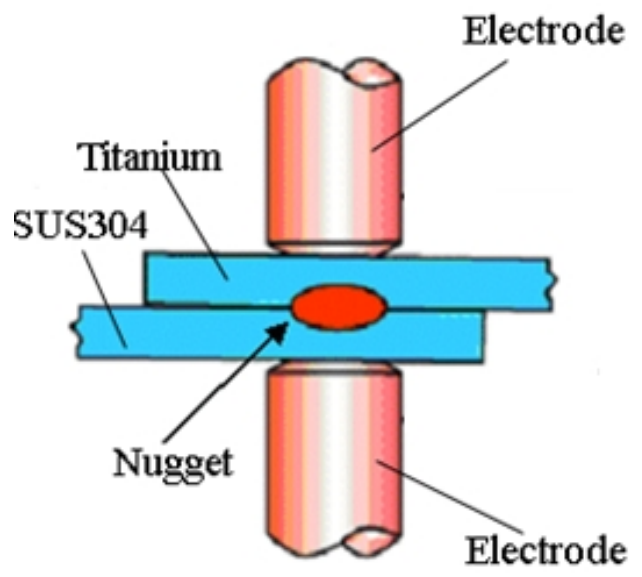

Fig.1 The schematic diagram of resistance spot welding

Fig.2 shows the shape and size of joints. The microstructure of joint was observed using a scanning electron microscope (SEM, JSM-5600, acceleration voltage: $20 \mathrm{kV}$ ). In order to examine the mechanical properties of the joints, the tensile-shear testing was performed at the speed of 1.0 $\mathrm{mm} / \mathrm{min}$ at room temperature. Listed in this paper, the results were the average value of the five joints for the welding under the same condition.

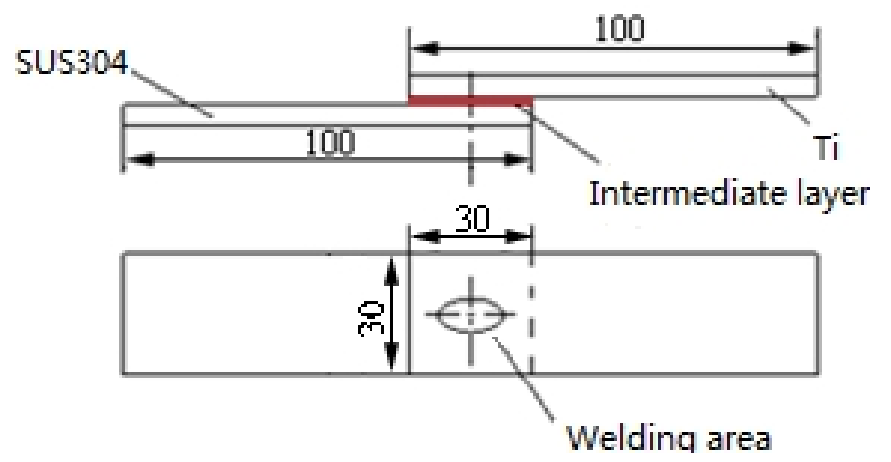

Fig. 2 Shape and size of specimen for welding

\section{RESULTS AND DISCUSSION}

\section{Microstructural analysis of $\mathrm{Ti} / \mathrm{Nb} / \mathrm{SUS304}$}

Fig. 3 shows SEM images of the interfacial region of the Ti/Nb/SUS304 joint, which was welded at the condition of welding current of $8 \mathrm{kA}$. As shown in Fig. 3(a), there are some obvious cracks forming in the center of nugget. The reason is that, the cracks are mainly due to differences in linear expansion coefficient of the base materials. In addition, $\mathrm{Nb}$ interlayer appeared a fusionbreak phenomenon. It is considered to be the temperature distribution at the welded region, high 
welding temperature at the central zone of the weld and low welding temperature at the peripheral, which lead to the fusion-break phenomenon of $\mathrm{Nb}$.
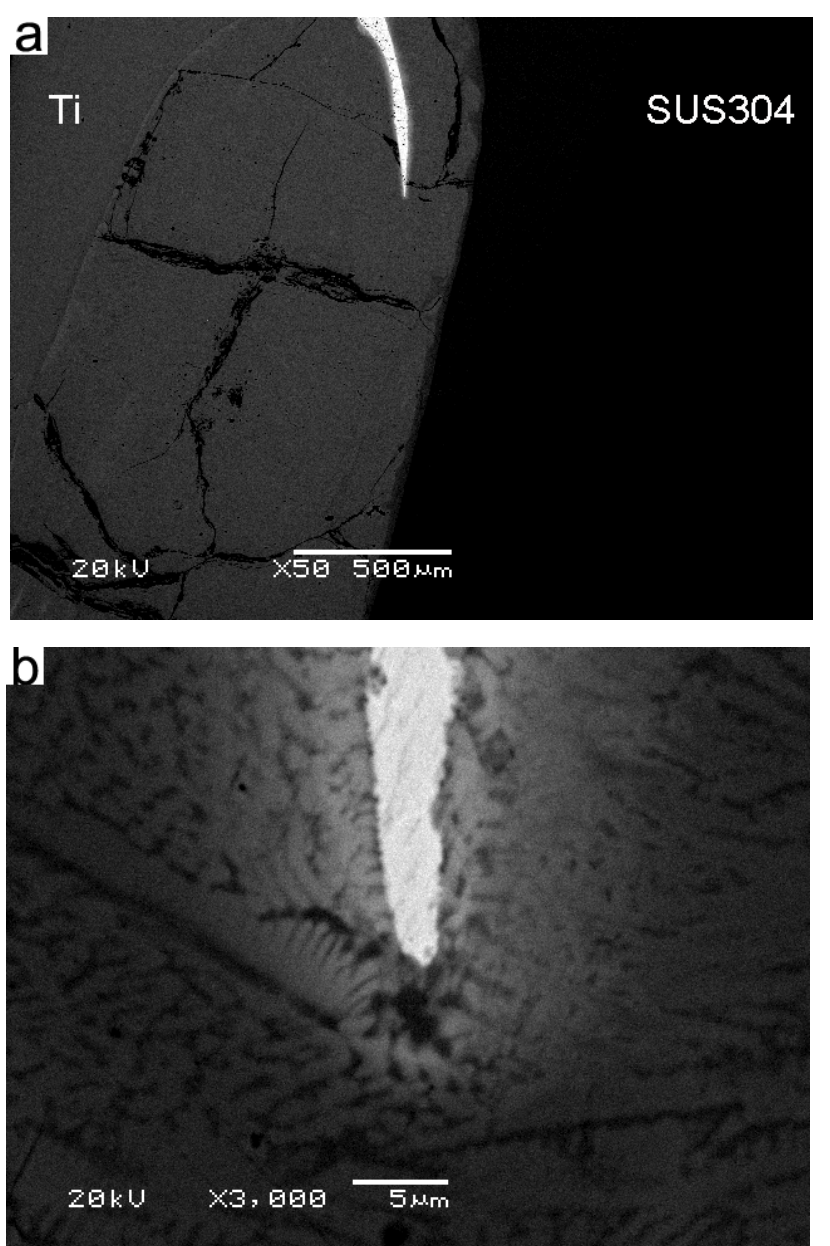

Fig. 3 SEM images of the interfacial region (8kA)

Fig. 3(b) shows an enlarged view of the fusion zone. In this image, comparing the thickness of $\mathrm{Nb}$ with that of pre-welding, the thickness of $\mathrm{Nb}$ was approximately $50 \mu \mathrm{m}$, which means $\mathrm{Nb}$ melt only $55 \%$. So the next step is to explore the microstructure by reducing the thickness of the $\mathrm{Nb}$ layer by $30-40 \mu \mathrm{m}$.

Fig. 4(a) shows the SEM image of the weld cross-section at the SUS304/Nugget interface. In this image, the fine needle-like reaction products with thickness of about $10 \mu \mathrm{m}$ were observed, which orientated towards the nugget and was flat in the SUS304 side. According to the binary phase diagram of $\mathrm{Fe}-\mathrm{Nb}$ and EDS results, it can be estimated that the reaction products were consisted of $\mathrm{Nb}$ and FeNb eutectic structure. As shown in Fig 4(b), the formation of new phase was observed at the Nugget/ Ti interface. As shown, the reaction layer front exhibited rod-like morphology in the Ti region side and smooth morphology near the welding interface. 

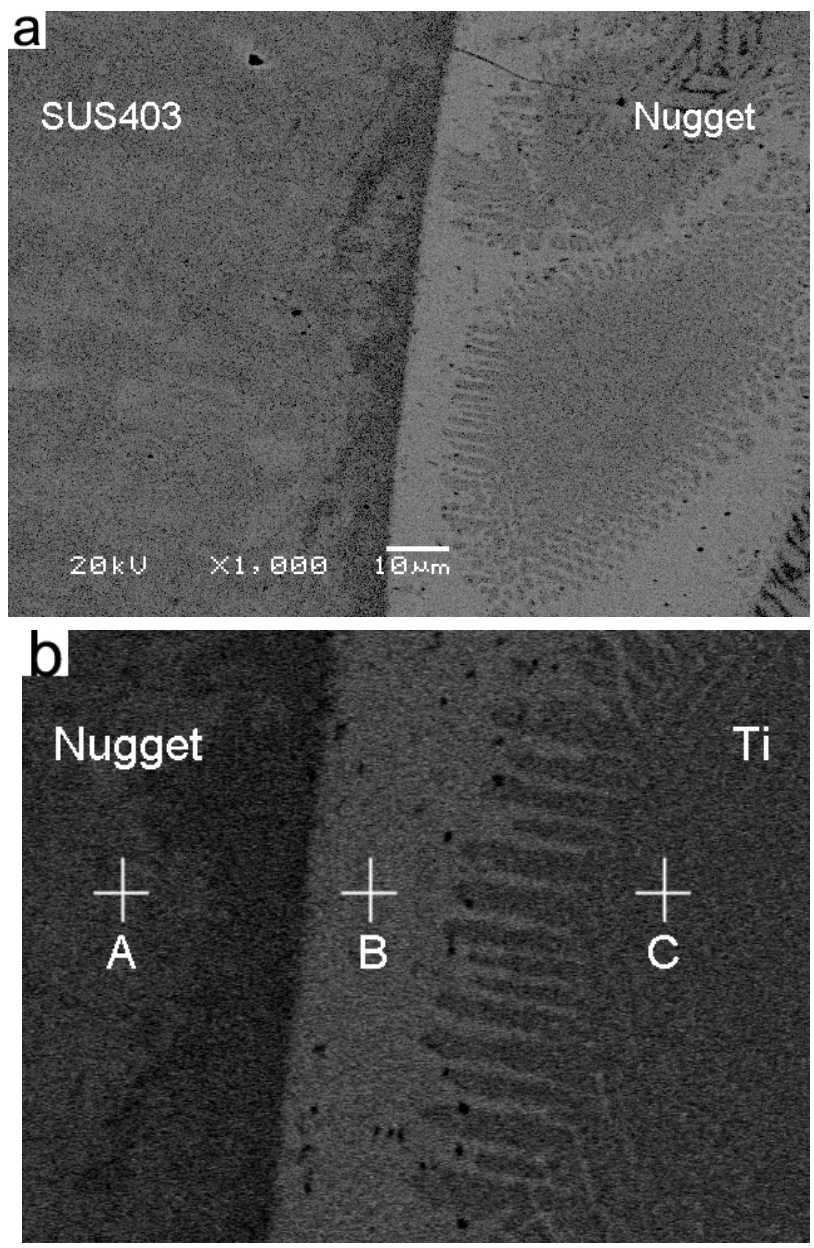

Fig. 4 SEM images the of the interfacial region SUS304/Nugget; (b) Nugget/ Ti

Fig.5 shows the EDS result for interfacial zone. As shown, $\mathrm{Nb}$ element appeared some small peaks. That is to say, the reaction layer contained a certain amount of $\mathrm{Nb}$. Moreover, the content of $\mathrm{Ti}$ and $\mathrm{Fe}$ changed relatively swing. It means that the interfacial reaction products were iron and titanium intermetallic compounds. Besides, the results reveal that a small quantity of $\mathrm{Cr}$ and $\mathrm{Ni}$ is contained in these phases.

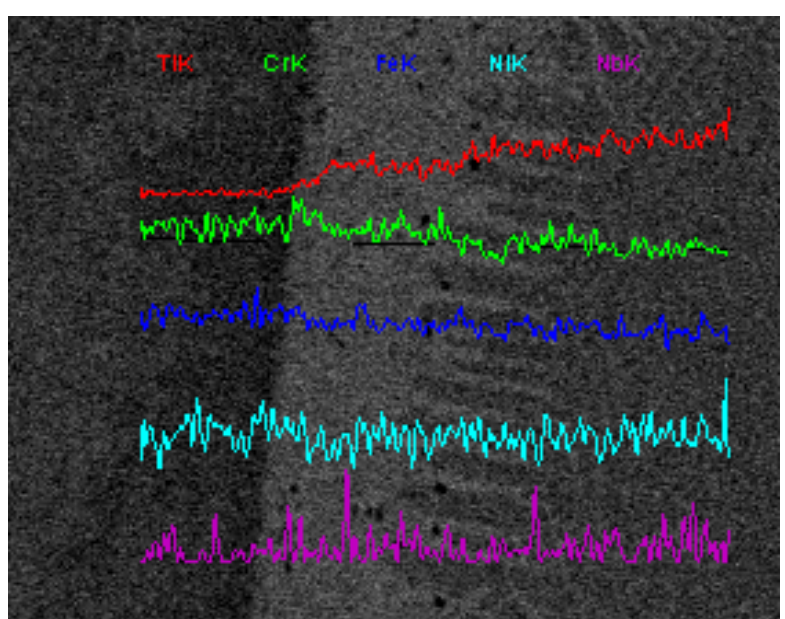

Fig. 5 Result of EDS composition test for interfacial zone

In order to clarify the detailed structure of the reaction products, the phases in the welded area were analyzed using EDS. The results are shown at table 2. According to binary phase diagram of $\mathrm{Fe}-\mathrm{Nb}$, we can infer that the intermetallic compounds (Position $\mathrm{B}$ ) are $\mathrm{Nb}$ and $\mathrm{FeNb}$ eutectic 
structure. In addition, $\mathrm{Nb}$ content appeared some small peak in the reaction layer, it is because that $\mathrm{Nb}$ has the same the atomic radius with $\mathrm{Ti}$, can easily occupy atomic vacancy of $\mathrm{Ti}$, and then, dissolved in compound.

Table.2 EDS analysis results of interfacial intermetallic compounds (at \%)

\begin{tabular}{cccccc}
\hline position & $\mathrm{Ti}$ & $\mathrm{Fe}$ & $\mathrm{Nb}$ & $\mathrm{Cr}$ & $\mathrm{Ni}$ \\
\hline $\mathrm{A}$ & 0.018 & 23.66 & 65.92 & 8.96 & 1.28 \\
$\mathrm{~B}$ & 7.54 & 18.77 & 64.69 & 7.74 & 1.26 \\
$\mathrm{C}$ & 12.57 & 12.13 & 70.08 & 4.00 & 1.22 \\
\hline
\end{tabular}

\section{Effect of welding current on mechanical properties of joints}

Fig. 6 and 7 shows the impact of welding current on the nugget diameter and tensile shear load of joint, respectively. As shown in Fig.6, with the increasing of welding current, the nugget diameter of the joint firstly increased and then remained flat. It is known that heat input in the welding zone follow the Joule's law. With welding current increasing, the heat input to the specimen increases. Increasing heat input enlarge weld nugget diameter. When the welding current reached 10KA, the nugget diameter decreased with the increasing of nugget diameter. This is because the restriction of the electrode diameter. In addition, according to the standard request of resistance spot welding nugget diameter: $\mathrm{d}>4 \mathrm{t}{ }^{0.5}$ (" $\mathrm{t}$ " is plate thickness). In this study, the plate thickness is $1 \mathrm{~mm}$, that means $\mathrm{d}>4 \mathrm{~mm}$. From Fig. 8 , it can be seen, changing the welding current from $8 \mathrm{kA}$ to $14 \mathrm{kA}$, nugget diameter is more than $7 \mathrm{~mm}$ all the time. The result meets the standard requirements of welding area.

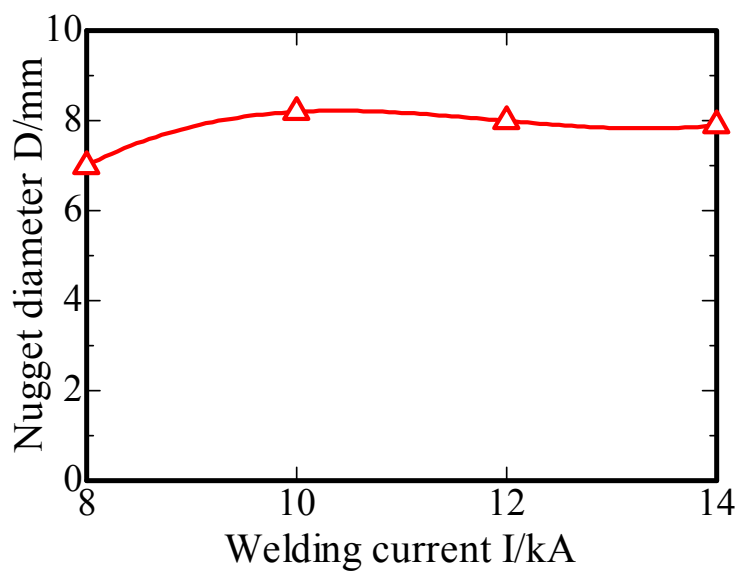

Fig.6 Effect of welding current on nugget diameter

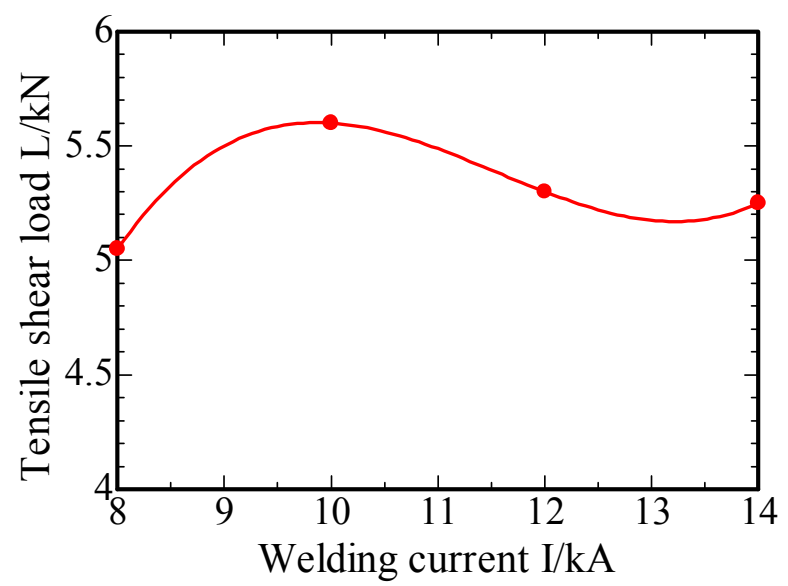

Fig. 7 Effect of welding current on tensile shear load

As shown in Fig.7, the Tensile shear load firstly increased with the increasing the nugget diameter and then gradually descended. The joint with the maximum tensile shear load of $5.61 \mathrm{kN}$ was obtained at the condition of 10kA. It is considered to be the tensile shear load is influenced by 
nugget size and thickness of the intermetallic compound formed at the welding zone. In the low current scope, the influence of nugget size on the tensile shear load is greater than the latter, while the thickness of intermetallic compound will be more important in the high current scope.

\section{CONCLUSION}

The interfacial reaction products were consisted of $\mathrm{Nb}$ and $\mathrm{FeNb}$ eutectic structure. The joint with the maximum tensile shear load of $5.61 \mathrm{kN}$ was obtained at the condition of $10 \mathrm{kA}$. It reveals that it is effective to weld titanium and stainless steel using resistance spot welding with an interlayer of $\mathrm{Nb}$.

\section{ACKNOWLEDGEMENT}

This work was supported by the Natural Science Foundation of China (grant no. U1204520), Henan Province Foundation and Advanced Technology Research Program (grant no. 122300410202), Henan Province College \& University Youth Backbone Teachers Found Project (grant no. 2013GGS-064). Natural Science Innovation Ability Cultivating Project of Henan University of Science and Technology (2014ZCX003); National Training Programs of Innovation and Entrepreneurship for Undergraduates (201310464023) and the project sponsored by SRF for ROCS, SEM.

\section{REFERENCES}

[1]. Wang Ting, Zhang binggang. Influences of different filler metals on electron beam welding of titanium alloy to stainless steel. Transactions of the china welding institution, 2013, (24): $108-114$

[2]. Kundu S, Ghosh M. Diffusion bonding of commercially pure titanium to 304 stainless steel using copper interlayer [J]. Materials Science and Technology, 2005(13): 154-160.

[3]. CC Liu, C Lou, RK. Shiue. The microstructural observation and wettability study of brazing Ti6Al-4V and 304 stainless steel using three braze alloys [J]. Mater. Sci. 2002, (37): 2225-2235.

[4]. P. Manikandan, K. Hokamoto. Control of energetic conditions by employing interlayer of different thickness for explosive welding of titanium/304 stainless steel [J]. Journal of materials processing technology, 2008, 37(3): 232-240. 